\title{
Implementation and evaluation of a harm- reduction model for clinical care of substance using pregnant women
}

Tricia E Wright ${ }^{1 *}$, Renee Schuetter ${ }^{2}$, Eric Fombonne ${ }^{3}$, Jessica Stephenson ${ }^{2}$ and William F Haning $1 \mathrm{I}^{4}$

\begin{abstract}
Background: Methamphetamine (MA) use during pregnancy is associated with many pregnancy complications, including preterm birth, small for gestational age, preeclampsia, and abruption. Hawaii has lead the nation in MA use for many years, yet prior to 2007, did not have a comprehensive plan to care for pregnant substance-using women. In 2006, the Hawaii State Legislature funded a pilot perinatal addiction clinic. The Perinatal Addiction Treatment Clinic of Hawaii was built on a harm-reduction model, encompassing perinatal care, transportation, child-care, social services, family planning, motivational incentives, and addiction medicine. We present the implementation model and results from our first one hundred three infants (103) seen over 3 years of operation of the program.

Methods: Referrals came from community health centers, hospitals, addiction treatment facilities, private physician offices, homeless outreach services and self-referral through word-of-mouth and bus ads. Data to describe sample characteristics and outcome was obtained prospectively and retrospectively from chart abstraction and delivery data. Drug use data was obtained from the women's self-report and random urine toxicology during the pregnancy, as well as urine toxicology at the time of birth on mothers, and urine and meconium toxicology on the infants. Post-partum depression was measured in mothers with the Edinburgh Post-Partum depression scale. Data from Path clinic patients were compared with a representative cohort of women delivering at Kapiolani Medical Center for Women and Children during the same time frame, who were enrolled in another study of pregnancy outcomes. Ethical approval for this study was obtained through the University of Hawaii Committee for Human Studies.
\end{abstract}

Results: Between April 2007 and August 2010, 213 women with a past or present history of addiction were seen, 132 were pregnant and 97 delivered during that time. 103 live-born infants were delivered. There were 3 firsttrimester Spontaneous Abortions, two 28-week intrauterine fetal deaths, and two sets of twins and 4 repeat pregnancies. Over $50 \%$ of the women had lost custody of previous children due to substance use. The majority of women who delivered used methamphetamine (86\%), either in the year before pregnancy or during pregnancy. Other drugs include marijuana (59.8\%), cocaine (33\%), opiates (9.6\%), and alcohol (15.2\%). Of the women served, $85 \%$ smoked cigarettes upon enrollment. Of the 97 women delivered during this period, all but 4 (96\%) had negative urine toxicology at the time of delivery. Of the 103 infants, $13(12.6 \%)$ were born preterm, equal to the state and national average, despite having many risk factors for prematurity, including poverty, poor diet, smoking and polysubstance use. Overwhelmingly, the women are parenting their children, $>90 \%$ retained custody at 8 weeks. Long-term follow-up showed that women who maintained custody chose long-acting contraceptive methods; while those who lost custody had a very high (> 50\%) repeat pregnancy rate at 9 months post delivery.

\footnotetext{
* Correspondence: tewright@hawaii.edu

'Department of Obstetrics, Gynecology and Women's Health, University of Hawaii John A. Burns School of Medicine, 1319 Punahou St., Ste. 824

Honolulu, HI 96826 USA

Full list of author information is available at the end of the article
}

\section{Biomed Central}

(c) 2012 Wright et al; licensee BioMed Central Ltd. This is an Open Access article distributed under the terms of the Creative Commons Attribution License (http://creativecommons.org/licenses/by/2.0), which permits unrestricted use, distribution, and reproduction in any medium, provided the original work is properly cited. 
Conclusion: Methamphetamine use during pregnancy doesn't exist is isolation. It is often combined with a multitude of other adverse circumstances, including poverty, interpersonal violence, psychiatric comorbidity, polysubstance use, nutritional deficiencies, inadequate health care and stressful life experiences. A comprehensive harm reduction model of perinatal care, which aims to ameliorate some of these difficulties for substance-using women without mandating abstinence, provides exceptional birth outcomes and can be implemented with limited resources.

Keywords: Methamphetamines, Harm Reduction, Pregnancy, Birth Outcomes, Tobacco

\section{Background}

Methamphetamine (MA) use by pregnant women has grown into the one of the greatest public health challenges of the $21^{\text {st }}$ century. Hawai'i arguably leads the nation in the use of MA, especially among women, given the highest percentages of female arrestees testing positive for MA use are located in Honolulu (50\%), San Jose (42.8\%), Phoenix (41.7\%), Salt Lake City (37.7\%), and San Diego (36.8\%) [1]. In addition, the use of MA by women of childbearing age is increasing [2-4]. Indeed MA has become the primary substance compelling drug treatment during pregnancy [5]. Yet despite this epidemic, prior to 2007, Hawaii did not have a comprehensive plan to care for pregnant substance-using women. In this paper, we review what is known about MA use in women and MA in pregnancy; the implementation model for a perinatal clinic; and results from the first 97 women to deliver.

\section{Women and Methamphetamine}

Men's rates of substance use disorders are nearly twice as high as the rate for females (11.9 vs. 6.1 percent) [6]. However, women use MA at similar rates as do men. The NSDUH 2009 data [6] showed that $0.2 \%$ of both men and women used MA in the past year. In 2007, females accounted for $40 \%$ of stimulant-related ED visits and $45 \%$ of MA-related treatment admissions in the United States [7]. In comparison, men are three times more likely to abuse alcohol and twice as likely to use cocaine than women [6]. Reasons for this discrepancy are multiple and need to be addressed during treatment.

\section{Co-occurring Disorders}

Women are more likely to have co-occurring mental health disorders; as many as two thirds of women with substance use disorders may have a co-occurring mental health problem, including depression, post-traumatic stress disorder, panic disorder and/or eating disorder [8]. They are more likely to be victims of domestic violence, incest, rape, sexual assault, and child physical abuse. This victimization has been linked to many negative outcomes, including posttraumatic stress disorder (PTSD), depression, anxiety, suicidal behavior and low self-esteem among women in the general population [9].
Women who are survivors of childhood sexual assault are more likely to use alcohol and other drugs $[10,11]$. Posttraumatic stress disorder is strongly associated with stimulant use disorders, including MA [12].

Methamphetamine, increasing the synaptic levels of not only dopamine, but also norepinephrine and serotonin, is a powerful antidepressant at first, which may partially explain its allure to women. Semple et al [13] showed that women who use MA had significantly higher Beck Depression Index scores than men who used MA. MA users in general have high levels of psychiatric symptoms and psychological problems. One study showed that women scored higher than men on every psychological symptom at treatment entry, especially anxiety, depression, interpersonal sensitivity, obsessive-compulsive disorder and somatization [14].

\section{Weight Loss}

In addition, many women begin using MA in order to lose weight, as many as $36 \%$ of women in one study vs. $7 \%$ of men [15]. Piran and Robinson [16] showed high rates of stimulant use among women with eating disorders. Corstorphine et al [17] showed that women with eating disorders who were victims of childhood sexual assault were more likely to use alcohol, cocaine or amphetamines. Gender roles stressing the thin-ideal body image may exacerbate the problem, especially among white, Native American and Pacific Island women [18].

\section{Caregiver role}

Women who must hold down multiple jobs, including caring for children often turn to MA to give them the extra energy they need to be "supermom." Though men more often than women use methamphetamine to "work more," and are more likely to be employed than women, women were more likely to use MA to stay awake [15].

\section{Cost}

The cost of drugs may play a large role in initiation. Women are more likely to live in poverty, and when they do get drugs, it is usually from a partner who is also using [15]. Methamphetamine acts longer than 
cocaine and other stimulants and before precursor legislation, cost less. One nickname for the drug is "poorman's cocaine." In addition, many studies have shown that women MA users are more likely to be homeless [19].

\section{Methamphetamines and Pregnancy}

Despite the widespread nature of MA use in women of childbearing age, little research has been done on its use during pregnancy. Most prior drug use research was conducted in response to the crack cocaine epidemic of the early 1980s. Much remains unknown about the effects of in utero MA exposure and fetal and infant development. No consistent teratological effects of in utero MA exposure on the developing human fetus have been identified [20,21]. Given that women with substance use disorders suffer from chaotic lifestyles, research on drug use during pregnancy is fraught with difficulties. Studies of MA-exposed infants suffer from methodological problems such as poor compliance, small sample size and multiple other confounding variables, such as the effects of poverty, poor diet, and tobacco use, which in studies of other drug use during pregnancy have been found to be as harmful if not more so than the drug use itself [22] Learning from past mistakes from the crack cocaine epidemic, Barry Lester and colleagues initiated the Infant Development, Environment, and Lifestyle (IDEAL) study in 2002 to study the effects of prenatal methamphetamine exposure. Investigators have enrolled 1,618 mothers at four clinical centers in cities where methamphetamine use is problematic, including Honolulu. Thus far the results from the IDEAL study indicate that methamphetamine is associated with fetal growth restriction [23], but no measurable difference in psychological functioning by age three [24].

There is some limited data on the effects of MA use on maternal complications during pregnancy [25-30]. With the exception of Cox et al [29], the numbers in these studies are all small and suffering from the methodological problems noted above. The Cox study showed increased risks of hypertension complicating pregnancy, premature rupture of membranes, placenta previa, placental abruption, premature delivery, precipitate labor, infection of amniotic cavity, intrauterine death, and poor fetal growth when compared with non-substance using women, but when compared with cocaine-using women, these risks were all less, with the exception of hypertension complicating pregnancy, which was increased over cocaine.

Studies looking at birth weight and gestational age show conflicting results, with most showing slightly smaller babies and lower gestational ages $[26,27,31,32]$. Studies on neurodevelopment [33-37] have shown MRI differences and small differences in performances on some developmental measures, but with the exception of the IDEAL study, longitudinal data is missing.

\section{Harm Reduction and Pregnancy}

With the exception of methadone maintenance, which is currently the standard of care for opiate-dependent pregnant women, harm reduction programs for pregnant substance-using mothers are rare, especially in the United States. As stated by McGourty and Chasnoff: "From a public health perspective, the concept of harm reduction does not have a role in the care of pregnant women [38]." Part of the problem is in the definition of harm reduction. It refers to both a philosophical approach and specific types of programs or interventions [39]. Perhaps McGourty and Chasnoff misconstrued that harm reduction means simply tolerating drug or alcohol use during pregnancy, which, especially in the case of alcohol, goes against the necessary teaching that no amount of alcohol is known to be safe during pregnancy [40].

Prenatal care has been shown to ameliorate many of the complications of drug use during pregnancy [41], so it makes empiric sense that a harm reduction philosophy as it facilitates entry into prenatal care, would decrease pregnancy complications. There has been little written on harm reduction programs for pregnant women, mostly originating from the U.K. and Canada, though programs certainly exist in the U.S. The literature on harm reduction in pregnancy from the U.S. mainly focuses on harm reduction by reducing use, not specific programs. One specific program in Canada has shown great promise with a harm reduction approach.

Poole stated in her evaluation of the Sheway project in British Columbia [42]:

Particularly promising is harm reduction programming offered to high-risk, marginalized pregnant women and their support networks, an approach that has been shown to prevent FAS and other alcohol- and drug-related disabilities, support retention of custody, and increase the health and social stability of both mothers and children

Key components of a harm reduction program should focus on improving nutrition, decreasing smoking, decreasing alcohol and drug use, encouraging breastfeeding, promoting dental health and encouraging physical activity, encouraging early and continuing prenatal care and promoting social and community support [43].

This review of the literature has shown many of the important concepts that must be addressed when providing care to pregnant women with substance use disorders. There are a few dozen programs that specifically 
provide care for pregnant substance-using women, but little in the literature evaluating their effectiveness. These concepts were used to build a comprehensive program, which is described below.

\section{Methods}

Context

The clinic concept was developed starting in March 2005 when a group of community leaders started meeting. Funding proposals were developed through a collaboration with the University of Hawaii, the Hawaii Departments of Human Services and Health, ACOG Hawaii Section and the Salvation Army Family Treatment Center, led by one of the authors (TEW). When federal grant proposals were not funded, the decision was made to appeal to the Hawaii State Legislature for funding. The Hawaii State Legislature passed legislation establishing the clinic in 2006 with the initial sum of $\$ 400,000$. The clinic model was developed with input from the University of Hawaii Ob/Gyn, Pediatrics and Addiction Medicine, and based on the successful Milagro clinic in Albuquerque, New Mexico. The clinic opened in April 2007 in a 1500 square foot house on the grounds of the Salvation Army Family Treatment Center.

\section{Clinic Mission}

Our mission is to provide comprehensive perinatal clinical and social services to women with a history of substance abuse, in a warm home-like setting free of judgment, and supportive of each woman's unique path from pregnancy to capable parent.

\section{Program Goals}

1. Improve birth outcomes in women who use drugs and/or alcohol during pregnancy.

2. Improve developmental and behavioral outcomes for children whose mothers used alcohol or other drugs during pregnancy.

3. Provide an educational environment for residents, students, and nurses to learn about the care of this high-risk population in a sensitive manner.

4. Provide educational resources to the community in order to decrease the prevalence of drug use among pregnant and postpartum women.

5. Provide an environment to promote research on substance abuse treatment, its effects on the mother, fetus, and child, and prevention.

\section{Clinic Services}

The initial clinic services began with prenatal and postpartum care. Deliveries were done by residents and staff of the University of Hawaii at Kapiolani Medical Center for Women and Children and Queens Medical Center.
Childcare was provided on site, transportation was provided either by taxi or by bus passes. Addiction psychiatry services were provided by addiction psychiatry and addiction medicine resident fellows under the supervision of one of the authors (WFH). Social services were provided on site, including case management, assistance with housing, substance abuse assessments and referral to more intensive treatment if indicated and desired. Group classes were provided including childbirth, parenting, smoking cessation, healthy eating, and relapse prevention. In addition, groups were established including self-nurturing group and craft groups to build selfesteem and enhance maternal infant bonding as well as relationship groups to address the needs of the women and their partners. Healthy food was provided to women while attending classes and clinic appointments, and by year three, we had obtained a grant from the Office of Hawaiian Affairs to provide a healing garden on site. With this garden, we were able to grow a good proportion of the fruits and vegetables provided to the women. While we were unable to engage the services of a dedicated pediatrician to meet goal (2) in the first three years of operation, collaboration and referrals were made with staff pediatricians at Kapiolani Medical center and sympathetic community pediatricians.

\section{Medical Care}

Prenatal visits were scheduled every 2 weeks, given the high-risk nature of these pregnancies, and the ability to engage women more frequently in social services if they came for medical care. Ultrasounds were generally scheduled every 4-8 weeks after 20 weeks to watch for intrauterine growth restriction and promote maternal bonding. As much as possible, all laboratory tests were done on site. Each woman received testing and counseling for HIV and Hepatitis C. Addiction psychiatry and group classes were scheduled around clinic visits.

\section{Counseling approach}

All clinic staff, including medical assistants and residents, was trained in Motivational Interviewing techniques [44], using a Stages of Change Model [45]. In addition, counseling was trauma informed $[46,47]$, given high rates of childhood sexual assault in the clinic population. As much as possible, a patient-centered harm reduction approach was used. Women were encouraged to participate in as many or as few activities as they were comfortable with.

\section{Motivational Incentives}

Contingency management, in which patients receive incentives or rewards for meeting specific behavioral goals (e.g., verified abstinence), has particularly strong, consistent, and robust empirical support across a range 
of types of drug use. Contingency management approaches are based on principles of behavioral psychology and operant conditioning, in which behavior that is followed by positive consequences is more likely to be repeated [48]. We received a grant from the local March of Dimes office to provide motivational incentives for women to help overcome barriers to clinic participation. Recognizing that getting clients through the door was the biggest barrier, the women received an initial $\$ 50$ gift card for their first visit. This was reduced to $\$ 20$ after the first year based on studies done by Petry and others recommending nominal and intermittent rewards [49]. After completion of the psychosocial assessment, they were awarded with an additional \$20 gift card. In addition, they received picks from the "fishbowl" for each subsequent doctor's visit, to reward group attendance and taking steps toward goal achievement. The fishbowl had small tokens saying "good job," "small," or "large." Small gifts were usually baby or toiletry items of nominal cost and the large gifts were $\$ 50$ gift cards.

\section{Ethical Approval}

The University of Hawaii Committee on Human Studies reviewed the project and found it to be exempt from consent requirements in order to report clinical outcomes.

\section{Outcomes}

Data to describe sample characteristics and outcome was obtained prospectively and retrospectively from chart abstraction and delivery data. Drug use data was obtained from the women's self-report and random urine toxicology during the pregnancy, as well as urine toxicology at the time of birth on mothers, and urine and meconium toxicology on the infants. Post-partum depression was measured in mothers with the Edinburgh Post-Partum depression scale, where a score of 10 or more is indicative of high levels of depressive symptomatology. For comparison, data on birth outcomes of Path clinic patients were compared with those of a representative cohort of women delivering at Kapiolani Medical Center for Women and Children during the same time frame, who had been recruited for the Pacific Research Center on Early Human Development study (PRCEHD). The data on this cohort has been presented in a previous paper [30].

\section{Statistical Analysis}

Data was analyzed using SAS 9.2 (Cary, NC). Conventional descriptive statistics were used. Dichotomous data were compared using chi-square and continuous data compared using student T-test. In order to further evaluate program effectiveness, we developed an outcome score in 4 separate domains: birth outcomes, drug use, custody, and repeat pregnancy. For each domain, several indicators were considered and scored with a binary coding scheme where 1 indicated a poor outcome and 0 an outcome within the normal range (see table five footnotes for the list of indicators mapping each outcome domain). The indicators scores were then summed up into a total domain score that was subsequently dichotomized into a $0 / 1$ binary summary score. For each domain score, we conducted a series of bivariate analyses of several candidate predictors, including engagement in prenatal care, parity, maternal medical condition, psychosocial variables (domestic violence, custody loss,..), drug use variables, and residential treatment status. Each candidate predictor was retained for logistic regression modeling based on a p-value $<0.25$ in bivariate analysis. Multiple logistic regression models were subsequently performed with stepwise selection of candidate predictors. Throughout, a p-value of 0.05 was retained as the criterion for statistical significance. The fit of multiple logistic regression models was assessed with the Hosmer-Lemeshow statistic.

Between April 2007 and August 31, 2010, 213 women were seen for medical care. These women all had a history of addiction and were either actively using or in early abstinence and thus at risk for relapse. There were 132 pregnant mothers and 97 of those delivered 103 live-born infants during that time, including two sets of twins and 4 repeat pregnancies. There were 3 first-trimester spontaneous abortions and two 28-week interuterine deaths (IUFD) thought to be secondary to cytomegalovirus (CMV) exposure. Patients were seen for a mean of 7 prenatal visits (range 1-19). Demographics are shown in table 1 .

Table 1 Demographics and clinical characteristics of Path women compared with a cohort of women delivering at the same hospital over the same timeframe

\begin{tabular}{llllll}
\hline & \multicolumn{2}{l}{ Path Clinic } & \multicolumn{2}{l}{ Kapiolani } & p-value \\
\hline Mean & SD & Mean & SD & \\
Age & 28.3 & 6.5 & 28.6 & 6.6 & 0.65 \\
Gravidity & 4.5 & 3.1 & 2.9 & 2.1 & $<0.001$ \\
Parity & 2.3 & 2.2 & 1.2 & 1.4 & $<0.001$ \\
Abortions & 1.2 & 1.9 & 0.7 & 1.1 & 0.01 \\
Gestational Age & 38.5 & 2.4 & 38.5 & 2.0 & 0.83 \\
Birth Weight & 3159.2 & 622.4 & 3189.9 & 552.2 & 0.61 \\
& $\mathrm{~N}=97$ & Percent & $\mathrm{N}=872$ & Percent & \\
Native Hawaiian & 47 & $49.5 \%$ & 193 & 22.1 & $<0.001$ \\
Smoking at delivery & 65 & $63 \%$ & 87 & $10 \%$ & $<0.001$ \\
Methamphetamines & & & & & \\
during pregnancy & 68 & 66 & 22 & 2.5 & $<0.001$ \\
\hline
\end{tabular}




\section{Medical Conditions}

There was a very high rate of asthma in the Path clinic group (28\%) compared with the Kapiolani cohort (KC) (3.7\%) $\mathrm{p}<0.001$. Chronic hypertension rates were also higher than in the $\mathrm{KC}$ sample $(9.9 \%$ vs. $4.5 \% \mathrm{p}=0.02)$. In the Path sample, there were no cases of HIV and $6.2 \%$ had Hepatitis C. There were two cases of maternal heart disease, which were possibly related to MA use. One woman had pregestational diabetes. Co-occurring mental health disorders were present in $36 \%$ of the women, including $27 \%$ with depression, $10 \%$ with diagnosed PTSD, and 5\% with bipolar disorder.

\section{Psychosocial Stressors}

In the Path sample, there were high rates of reported interpersonal violence, including $55 \%$ with a history of child-abuse or neglect and $62.5 \%$ with a history of domestic violence. Ninety five percent of the women were on Medicaid.

\section{Drug use}

MA was overwhelmingly the drug of choice for these women (86\%), though twenty-four percent used more than one drug. Almost all women stopped or decreased the use of drugs, with equal amounts of women becoming abstinent in each trimester and only $6.3 \%$ continuing to use until delivery. Only $5 \%$ of the infants' toxicology screens were positive. Of the eight opiate-dependent women (one woman only admitted to using occasional "pills" including oxycodone), 5 were on methadone maintenance, 1 was on buprenorphine, and 2 women were detoxified before being admitted to residential treatment and before coming to the clinic. Drug use characteristics are shown in table 2 .

Eighty four percent of the women smoked at the beginning of pregnancy, and only 14 percent of women were able to quit during pregnancy, though 34 percent decreased usage.

Pregnancy complications and birth outcomes are listed in table 3 . There were higher rates of preeclampsia in the Path sample compared with the KC sample, but most other pregnancy complications, notably preterm delivery, low birth weight, and cesarean delivery rates showed no difference. We have no comparison data for infant outcomes in the $\mathrm{KC}$ data, but rates of newborn intensive care admissions in the Path sample are relatively low, and 88.1 percent of infants were discharged with their mothers. There were no cases of intraventricular hemorrhages, necrotizing enterocolitis or neonatal death. Of 58 neonates for whom we have full pediatric information, there was only one major anomaly diagnosed shortly after birth and 5 minor anomalies, including 3 hydroceles and 2 minor digit defects.
Table 2 Substance Use Characteristics

\begin{tabular}{lll}
\hline Drug Use & $\mathbf{N}=\mathbf{9 7}$ & $\mathbf{\%}$ \\
\hline Methamphetamines & 87 & 86.1 \\
1st trimester & 19 & 19.8 \\
2nd trimester & 22 & 22.9 \\
$3^{\text {rd }}$ trimester & 21 & 21.9 \\
Continuous & 6 & 6.3 \\
Cocaine & 30 & 33 \\
Marijuana & 55 & 59.8 \\
Opiates & 9 & 9.6 \\
Smoker & 79 & 84 \\
Alcohol & 14 & $15.211-1$ st trimester use \\
Baby toxicology + (mec or & 4 & 0.1 \\
urine) & & \\
Smoking & 15 & 16 \\
Non-Smoker & 14 & 15 \\
Quit during pregnancy & 34 & 36 \\
Decreased during pregnancy & 30 & 32 \\
Stayed same & 1 & 1.1 \\
Increased & & \\
\hline
\end{tabular}

Table 3 Pregnancy complications

\begin{tabular}{|c|c|c|c|c|c|}
\hline & Path & & Kapiolani & & $p$ \\
\hline & $\mathrm{N}$ & Percent & $\mathrm{N}$ & Percent & \\
\hline IUGR & 5 & $5.0 \%$ & N/A & & \\
\hline Preeclampsia & 11 & 11.0 & 35 & 4.0 & 0.0025 \\
\hline Preterm labor & 11 & 10.9 & 112 & 12.8 & 0.58 \\
\hline PPROM & 6 & 5.9 & 28 & 3.2 & 0.16 \\
\hline Abruption & 2 & 2.0 & $\mathrm{~N} / \mathrm{A}$ & & \\
\hline Diabetes & 8 & 8.0 & 113 & 12.9 & 0.22 \\
\hline Oligohydramnios & 3 & 3.0 & 23 & 2.6 & 0.84 \\
\hline Previa & 1 & 1.0 & $\mathrm{~N} / \mathrm{A}$ & & \\
\hline Chorioamnionitis & 6 & 5.9 & N/A & & \\
\hline $\begin{array}{l}\text { Non-reassuring fetal } \\
\text { heart }\end{array}$ & & & $\mathrm{N} / \mathrm{A}$ & & \\
\hline tones & 6 & 5.9 & & & \\
\hline Polyhydramnios & 6 & 5.9 & $\mathrm{~N} / \mathrm{A}$ & & \\
\hline Cesarean section & 34 & 33.0 & 252 & 29.0 & 0.39 \\
\hline Delivery < 37 weeks & 13 & 12.6 & 131 & 15.0 & 0.70 \\
\hline Delivery < 32 weeks & $1^{*}$ & 0.9 & 14 & 1.6 & 0.80 \\
\hline LBW & 14 & 13.6 & 85 & 9.7 & 0.22 \\
\hline VLBW & $2^{*}$ & 1.9 & 10 & 1.1 & 0.49 \\
\hline NICU admission & 15 & 16.1 & $\mathrm{~N} / \mathrm{A}$ & & \\
\hline Hypoglycemia & 3 & 4.7 & $\mathrm{~N} / \mathrm{A}$ & & \\
\hline Hyperbilirubin & 11 & 10.8 & $\mathrm{~N} / \mathrm{A}$ & & \\
\hline sepsis & 1 & 1 & N/A & & \\
\hline RDS & 5 & 4.9 & $\mathrm{~N} / \mathrm{A}$ & & \\
\hline
\end{tabular}

* 1 set of twins. 1 very preterm birth, but 2 very low-birth weight infants. $\mathrm{EBL}=$ estimated blood loss, LBW $=$ low birth weight $<2500 \mathrm{~g}, \mathrm{VLBW}=$ very low birth weight $<1500 \mathrm{~g}, \mathrm{NICU}=$ neonatal intensive care unit, RDS = respiratory distress syndrome, $\mathrm{IVH}=$ interventricular hemorrhage 
Table 4 Postpartum follow-up

\begin{tabular}{lll}
\hline & $\boldsymbol{n}$ & \% \\
\hline Postpartum Depression & 22 & 21.4 \\
LARC & 28 & 28 \\
Sterilization & 14 & 14 \\
OCPS/Ring & 12 & 12 \\
DMPA & 7 & 7 \\
None & 15 & 15 \\
Lost & 22 & 22 \\
Female Partner only & 2 & 2 \\
Repeat pregnancy & 13 & 17 \\
\hline DMPA
\end{tabular}

DMPA=depo medroxyprogesterone acetate, LARC=long-acting reversible contraception. OCPS=oral contraceptive pills.

\section{Post-Partum}

Data on post-partum follow-up, including incidence of post-partum depression, contraceptive methods, and repeat pregnancy rates are shown in table 4.

Twenty-one percent of women screened positive for possible postpartum depression with an Edinburgh postpartum depression scale of over 10. Twenty eight percent of women chose long-acting reversible contraception and 14\% chose sterilization. Overall, 63\% of women chose some form of contraception immediately post-partum.

\section{Analysis of poor outcomes}

\section{Outcome analyses}

Outcome analysis is presented in table 5 . The table summarizes 4 independent logistic regression models for each of the 4 outcomes considered. For each

Table 5 Predictors of poor outcomes in $\mathbf{4}$ domains

\begin{tabular}{lll}
\hline Infant Poor Outcomes* & AOR & $\begin{array}{l}95 \% \text { confidence interval } \\
\text { Parity }\end{array}$ \\
$\begin{array}{l}\text { History of Domestic } \\
\text { Violence }\end{array}$ & 5.7 & $(1.3-26.6)$ \\
$\begin{array}{l}\text { Maternal Medical } \\
\text { Condition }\end{array}$ & 4.6 & $(1.1-18.9)$ \\
$\begin{array}{l}\text { Drug Use Poor Outcomes** } \\
\text { Residential Treatement }\end{array}$ & 0.17 & $(0.031-0.95)$ \\
$\begin{array}{l}\text { Poor prenatal care } \\
\text { Custody Loss Poor Outcomes*** }\end{array}$ & 12.7 & $(2.8-57.1)$ \\
$\begin{array}{l}\text { Residential Treatement } \\
\text { 3rd trimester drug use }\end{array}$ & 0.035 & $(0.004-0.3)$ \\
Family Planning Poor Outcome & 7.9 & $(2.2-27.6)$ \\
Custody loss & & \\
\hline
\end{tabular}

Note: each domain summarizes outcome as measured by the following indicator variables:

*preterm delivery, LBW, NICU admission, baby Length of stay $>4$ days ** positive toxicology at birth (mom or baby), relapse within 6 months ***not discharged with baby (secondary to child welfare) or lost custody within 6 months.

****not on birth control postpartum or repeat pregnancy within 6 months outcome, only predictors that were significant at $\mathrm{p}<$ 0.05 are presented in the Table, with their corresponding odds-ratio adjusted for the effects of other predictors.

Infant outcomes were influenced by maternal parity (protective), maternal medical conditions, and domestic violence, when controlled for amount of prenatal care and homelessness. Drug use was most heavily influenced by residential treatment (highly protective) and lack of prenatal care. Loss of custody was also strongly associated with the protective presence of residential treatment $(\mathrm{AOR}=0.035)$ and an eight-fold increase in risk due to third trimester drug use. Family planning failure was associated with custody loss.

\section{Discussion}

This paper shows the success and challenges in caring for this high-risk population. Women in this study had high rates of co-occurring medical and mental health problems, high poverty rates, high rates of interpersonal violence, and high smoking rates. Despite these challenges, with the appropriate interventions and care, women with addictions can have relatively normal birth outcomes. Previous work by one of the authors showed a 4-fold increased risk of preterm delivery with methamphetamine use in this population [30]. We definitely did not see this increase, as our preterm delivery rate was not different from the cohort from the same hospital, as well as state and national averages (12.8 and 12.3 respectively) [50]. We did see increased preeclampsia rates, which are not surprising as asthma, chronic hypertension, and methamphetamine use are all associated with preeclampsia [29].

By providing a safe environment to obtain prenatal care, we ameliorated many the effects of the drug use, especially preterm delivery rates. We have shown that increased prenatal visits, which roughly translates into participation with other clinic services is associated with increased abstinence and decreased relapse postpartum, though this could be a result of selection bias. Other authors have shown this with other drugs [51]. Quality prenatal care of at least 4 visits has been shown to significantly improve birth outcomes, decrease preterm delivery, and increase fetal birth weights [41]. Studies with cocaine-using pregnant women demonstrate that "comprehensive care" increases the likelihood of carrying to term, having fewer complications, being drug free at delivery, and having fewer exposed repeat pregnancies [52].

Our experience has shown us the importance of a comprehensive approach to treating women with addiction. It is important to address all components of the woman's life, including work and family: As one of our clients said, "I began using because I was working 
nights. My parents don't speak English and have many health problems, so I would have to get up after just and hour or two of sleep and take them to their doctors' appointments. I used ice [MA] to have energy to do that." Addressing nutrition is very important for example, as weight gain can be a powerful trigger for relapse, especially postpartum. One woman in our clinic stated that she was very unhappy with her weight postpartum which hadn't been a problem with her past pregnancies as she "just started using again and the weight came right off."

We believe a harm-reduction approach does work with these women, as we had high rates of engagement in services. As the clinic is in a house, many women stated they felt extremely comfortable there and would come when in crisis or just "to hang out." We had very high rates of abstinence during pregnancy, despite not mandating an abstinence-only approach. We believe this approach encourage honesty about their use. The women felt very comfortable discussing their use, and many times would disclose their relapses before a positive toxicology result was obtained.

Another success is the relatively low rates of post-partum depression, being fairly comparable to populationbased rates of 14-21\% [53,54], given the high incidence of antecedent depression in this population, and that a history of depression is one of the biggest risk factor in postpartum depression [53]. Having a safe, supportive environment postpartum was cited by many women as helpful to their general wellbeing.

The low rates of HIV and Hepatitis C point to the success of other harm reduction approaches; Hawaii was the first state in the nation to have a syringe-exchange program, which has been operating since 1990 and the majority of women in Hawaii smoke MA rather than inject.

The high rates of asthma are concerning, exceeding Hawaii's traditionally elevated rates of approximately $11 \%$ of the female population [55], and there are multiple explanations: higher asthma rates among Native Hawaiians; extremely high smoking rates in this population, and possibly the concomitant use of albuterol with MA to potentiate its effects. The high percentage of Native Hawaiians in this clinic population points to a large health disparity, which we have described before [30], and needs to be addressed with community-based research models.

The protective effect of residential treatment is seen within the drug use and custody domains. This result is to be expected as the residential treatment facility is the only one on the island of Oahu that allows women to bring a child into treatment with them. Women often chose this center in order to maintain custody. This type of program has demonstrated success in other areas and should be expanded.
The effect of a history of domestic violence on poor infant outcome is somewhat surprising, but not entirely unexpected, given high levels of psychosocial stress is associated with higher cortisol levels, and worse pregnancy outcomes [56]. Not surprising is the effect of maternal medical conditions on infant outcomes. Women should ideally enter pregnancy in optimal health, medically as well as mentally to insure the health of the infant.

While the majority of women were able to stop using drugs during pregnancy, they continued to smoke cigarettes. This is concerning given emerging data by us and others that smoking may be more harmful than MA use (at least on measurable pregnancy outcomes) [23] (Wright et al: The placental and pregnancy effects of methamphetamines and smoking, submitted) Chang, L. et al (personal communication, Hawaii Addictions Conference, March 19, 2010). While the numbers are too small to show any association with MA and congenital anomalies, it is reassuring that there were no large increases in these rates over baseline.

These women have high gravidity and parity, and a majority of these women have previously lost custody of at least one child. Most of the women in the "none" category were clients of a six-month residential treatment facility which permitted no sexual contact and thus thought themselves not to be at risk for pregnancy. Of the 78 women we have information on, only $17 \%$ became pregnant again within 18 months. Statewide, $21 \%$ of Medicaid women became pregnant within 15 months [57]. We showed that women who lost custody were 2.5 times more likely to not use reliable contraception and have repeat pregnancies. Helping women maintain custody seems to encourage women to chose reliable contraception. Our low repeat pregnancy rates is a great success.

There is room for improvement in the postpartum period, however, as $22 \%$ of the women were lost to follow-up. Of the women who did follow up, there was a $13 \%$ relapse rate to heavy usage at 6 months. Addition of pediatric care will help to keep women involved with the clinic, and allow long-term follow-up of the children and their outcomes.

\section{Conclusion}

Methamphetamine use during pregnancy doesn't exist is isolation. It is often combined with a multitude of other adverse circumstances, including poverty, interpersonal violence, psychiatric comorbidity, polysubstance use, nutritional deficiencies, inadequate health care and stressful life experiences. A harm-reduction approach, which aims to ameliorate some of these difficulties for substance-using women without mandating abstinence, can work to engage women into prenatal care and 
normalize birth outcomes. This model provides an inexpensive and cost-effective approach (as the cost of one preterm infant can exceed the $\$ 200,000$ annual cost of the program [56]) to affect community-wide change. Having a clinic available in the community seemed to improve screening rates for substance use disorders in the community physicians, as there was a resource available for referral of these often-marginalized women and their families. Directions for further study would be to compare a harm reduction approach to traditional treatment paradigm, e.g. adding cognitive behavioral therapy (CBT). Also a comparison study of MA-exposed pregnancies to non-MA exposed pregnancies will be possible with the addition of additional women in the non-MA group. Certainly the pediatric follow-up will add longterm longitudinal data on the effects of MA on the children and help guide interventions to ameliorate the damage.

\section{Consent}

The University of Hawaii Committee on Human Studies reviewed the project and found it to be exempt from consent requirements in order to report clinical outcomes. A copy of the exemption is available for review by the Editor-in-Chief of the journal.

\section{Author Information}

TW is an Assistant Professor of Obstetrics, Gynecology and Women's Health and Clinical Assistant Professor of Psychiatry and Addiction Medicine at the University of Hawaii John A. Burns School of Medicine. RS was clinic manager and executive director of the Path Clinic. EF is Canada Research Chair Child Psychiatry, McGill University. WFH is Professor and Program Director in Addiction Psychiatry University of Hawaii John A. Burns School of Medicine.

\section{List of abbreviations}

ACOG: American College of Obstetrics and Gynecology; AOR: adjusted odds ratio; CBT: cognitive behavioral therapy; CMV: cytomegalovirus; FAS: fetal alcohol syndrome; HIV: Human Immunodeficiency Virus; IDEAL: Infant Development, Environmental, and Lifestyle; MA: methamphetamines; MRI: magnetic resonance imaging; NICU: newborn intensive care; PATH: Perinatal Addiction Treatment of Hawaii; PTSD: post traumatic stress disorder

\section{Acknowledgements}

The clinic was funded in part by Hawaii State Legislative Acts 248 and 147. Funding for motivational incentives was provided by the Hawaii Chapter of the March of Dimes. Funding for clinical outcomes studies was provided by $\mathrm{NIH}$ grant 5U54RR014607. The authors would also like to thank The Office of Hawaii Affairs, The Hawaii Community Foundation, Healthy Mothers, Healthy Babies-Hawaii, and other philanthropic supporters for their continued support; Drs. Mishka Terplan and Timothy Dye for their help in reviewing the paper drafts; Linda Rich and the Salvation Army Family Treatment Center for our peaceful coexistence; Nancy Partika for all her help negotiating the state legislative system; the Path Clinic Board of Directors, and all the clinic staff and volunteers, especially Bernadette Scanlan-Hodges Julia Yoshimoto, and Rachel Dorr, without whom this would be possible.

\section{Author details}

'Department of Obstetrics, Gynecology and Women's Health, University of Hawaii John A. Burns School of Medicine, 1319 Punahou St., Ste. 824, Honolulu, HI 96826 USA. ${ }^{2}$ Perinatal Addiction Treatment of Hawaii, $84522^{\text {nd }}$. Ave., Honolulu, HI 96816. USA. ${ }^{3}$ Department of Child Psychiatry, McGill University, 845 Sherbrooke Street West, Montreal, Quebec, H3A 2T5, Canada. ${ }^{4}$ Department of Psychiatry, University of Hawaii John A. Burns School of Medicine, 1356 Lusitana St., $4^{\text {th }}$ Floor, Honolulu, HI 96813 USA.

\section{Authors' contributions}

TW obtained funding for clinic initiation, developed clinic design, designed study, drafted and submitted completed paper. RS assisted in clinic development, managed clinical operations, aided in data collection, and contributed to paper development. EF reviewed statistical analyses and developed outcome-scoring system. JS designed data collection form and completed the bulk of data collection. WFH assisted in the development of the clinic model, sat on the Path Clinic Board of Directors, provided psychiatric training and support. All authors read and approved the final manuscript.

\section{Competing interests}

The authors declare that they have no competing interests.

Received: 9 September 2011 Accepted: 19 January 2012

Published: 19 January 2012

\section{References}

1. NIH: National Institute of Justice: Preliminary Data on Drug Use and Related Matters Among Adult Arrestees and Juvenile Detainees. 2003.

2. Anglin MD, Burke C, Perrochet B, Stamper E, Dawud-Noursi S: History of the methamphetamine problem. J Psychoactive Drugs 2000, 32:137-141.

3. NIH: Epidemiologic Trends in Drug Abuse Advance Report. 2002.

4. NIH: Research Reports: Methamphetamine Abuse and Addiction. 2002.

5. Terplan M, Smith EJ, Kozloski MJ, Pollack HA: Methamphetamine use among pregnant women. Obstet Gynecol 2009, 113:1285-1291.

6. SAMHSA: Results from the 2009 National Survey on Drug Use and Health: Volume I. Summary of National Findings (Office of Applied Studies, NSDUH Series H-38A, HHS Publication No. SMA 10-4856 Findings). Rockville, MD. 2010.

7. SAMHSA Office of Applied Studies: National Estimates of Drug-Related Emergency Department Visits. 2007.

8. Zilberman ML, Tavares H, Blume SB, el-Guebaly N: Substance use disorders: sex differences and psychiatric comorbidities. Can J Psychiatry 2003, 48:5-13.

9. Gil-Rivas V, Fiorentine R, Anglin MD: Sexual abuse, physical abuse, and posttraumatic stress disorder among women participating in outpatient drug abuse treatment. J Psychoactive Drugs 1996, 28:95-102.

10. Najavits LM, Weiss RD, Shaw SR: The link between substance abuse and posttraumatic stress disorder in women. A research review. Am J Addict 1997, 6:273-283.

11. Simpson TL, Miller WR: Concomitance between childhood sexual and physical abuse and substance use problems. A review. Clin Psychol Rev 2002, 22:27-77.

12. Smith RC, Blumenthal $H$, Badour C, Feldner MT: An investigation of relations between crystal methamphetamine use and posttraumatic stress disorder. Addict Behav 2010, 35:625-627.

13. Semple SJ, Zians J, Strathdee SA, Patterson TL: Psychosocial and behavioral correlates of depressed mood among female methamphetamine users. J Psychoactive Drugs 2007, Suppl 4:353-366.

14. Cohen JB, Greenberg R, Uri J, Halpin M, Zweben JE: Women with methamphetamine dependence: research on etiology and treatment. $J$ Psychoactive Drugs 2007, Suppl 4:347-351.

15. Brecht ML, O'Brien A, von Mayrhauser C, Anglin MD: Methamphetamine use behaviors and gender differences. Addict Behav 2004, 29:89-106.

16. Piran N, Robinson S: The association between disordered eating and substance use and abuse in women: a community-based investigation. Women Health 2006, 44:1-20.

17. Corstorphine E, Waller G, Lawson R, Ganis C: Trauma and multi-impulsivity in the eating disorders. Eat Behav 2007, 8:23-30

18. Bates B: Body image varies greatly among Asian groups. Clinical Psychiatry News 2004. 
19. Lorvick J, Martinez A, Gee L, Kral AH: Sexual and injection risk among women who inject methamphetamine in San Francisco. J Urban Health 2006, 83:497-505.

20. Plessinger MA: Prenatal exposure to amphetamines. Risks and adverse outcomes in pregnancy. Obstet Gynecol Clin North Am 1998, 25:119-138.

21. Briggs GG, Freeman RK, Yaffe SJ: Drugs in Pregnancy and Lactation. In Drugs in Pregancy and Lactation. Edited by: Siegafuse S and Shaw R. Philadelphia: Lippincot Williams 2007:

22. Schempf A: Illicit drug use and neonatal outcomes: a critical review. Obstet Gynecol Surv 2007, 62:749-757.

23. Smith LM, LaGasse LL, Derauf C, Grant P, Shah R, Arria A, Huestis M, Haning W, Strauss A, Della Grotta S, et al: The infant development, environment, and lifestyle study: effects of prenatal methamphetamine exposure, polydrug exposure, and poverty on intrauterine growth. Pediatrics 2006, 118:1149-1156.

24. Lester BM, Lagasse LL: Children of addicted women. J Addict Dis 2010, 29:259-276.

25. Eriksson M, Larsson G, Zetterstrom R: Amphetamine addiction and pregnancy. II. Pregnancy, delivery and the neonatal period. Sociomedical aspects. Acta Obstet Gynecol Scand 1981, 60:253-259.

26. Oro AS, Dixon SD: Perinatal cocaine and methamphetamine exposure: maternal and neonatal correlates. J Pediatr 1987, 111:571-578.

27. Little BB, Snell LM, Gilstrap LC: Methamphetamine abuse during pregnancy: outcome and fetal effects. Obstet Gynecol 1988, 72:541-544.

28. Albertson TE, Derlet RW, Van Hoozen BE: Methamphetamine and the expanding complications of amphetamines. West J Med 1999, 170:214-219.

29. Cox S, Posner SF, Kourtis AP, Jamieson DJ: Hospitalizations with amphetamine abuse among pregnant women. Obstet Gynecol 2008, 111:341-347

30. Wright TE, Tam E: Disparate rates of persistent smoking and drug use during pregnancy of women of Hawaiian ancestry. Ethn Dis 2010, 20: S1-215-218.

31. Smith L, LaGasse L, Derauf C, Lester B: Intrauterine Growth of Infants Exposed to Prenatal Methamphetamine: Preliminary Results from the Infant Development, Environment, and Lifestyle Study (IDEAL). Pediatric Research 2004, 55:72A

32. Smith L, Yonekura ML, Wallace $\mathrm{T}$, Berman $\mathrm{N}$, Kuo J, Berkowitz C: Effects of prenatal methamphetamine exposure on fetal growth and drug withdrawal symptoms in infants born at term. J Dev Behav Pediatr 2003, 24:17-23.

33. Chang L, Alicata D, Ernst T, Volkow N: Structural and metabolic brain changes in the striatum associated with methamphetamine abuse. Addiction 2007, 102(Suppl 1):16-32.

34. Chang L, Cloak C, Jiang CS, Farnham S, Tokeshi B, Buchthal S, Hedemark B, Smith LM, Ernst T: Altered neurometabolites and motor integration in children exposed to methamphetamine in utero. Neuroimage 2009, 48:391-397.

35. Chang L, Smith LM, LoPresti C, Yonekura ML, Kuo J, Walot I, Ernst T: Smaller subcortical volumes and cognitive deficits in children with prenatal methamphetamine exposure. Psychiatry Res 2004, 132:95-106.

36. Cloak CC, Ernst T, Fujii L, Hedemark B, Chang L: Lower diffusion in white matter of children with prenatal methamphetamine exposure. Neurology 2009, 72:2068-2075.

37. Smith LM, Chang L, Yonekura ML, Grob C, Osborn D, Ernst T: Brain proton magnetic resonance spectroscopy in children exposed to methamphetamine in utero. Neurology 2001, 57:255-260.

38. McGourty R, Chasnoff I: Power Beyond Measure Chicago, Illinois: NTI Publishing; 2003.

39. Ritter A, Cameron J: A review of the efficacy and effectiveness of harm reduction strategies for alcohol, tobacco and illicit drugs. Drug Alcohol Rev 2006, 25:611-624

40. SAMHSA: What You Need To Know. The Effect of Alcohol on a Fetus. DHHS Publication No (SMA) 07-4275 2007.

41. El-Mohandes A, Herman AA, Nabil El-Khorazaty M, Katta PS, White D, Grylack L: Prenatal care reduces the impact of illicit drug use on perinatal outcomes. J Perinatol 2003, Jul-Aug:354-360.

42. Poole N: Evaluation report of the Sheway Project for high-risk pregnant and parenting women. Vancouver, British Columbia: British Columbia Centre of Excellence for Women's Health; 2000.
43. Macrory F, Boyd SC: Developing primary and secondary services for drug and alcohol dependent mothers. Semin Fetal Neonatal Med 2007, 12:119-126.

44. Miller WR, Resnick S: Motivational interviewing: preparing people for change. 2 edition. New York, NY: The Guilford Press; 2002

45. Prochaska JO: Systems of psychotherapy: A transtheoretical analysis Homewood. Illinois: Dorsey Press; 1979.

46. Najavits LM: Seeking Safety New York, NY: The Guilford Press; 2002.

47. Covington SS: A Woman's way through the twelve steps Center City, Minnesota: Hazelden; 1994

48. Carroll KM, Onken LS: Behavioral therapies for drug abuse. Am J Psychiatry 2005, 162:1452-1460

49. Petry NM, Simcic F Jr: Recent advances in the dissemination of contingency management techniques: clinical and research perspectives. J Subst Abuse Treat 2002, 23:81-86.

50. Perinatal Statistics. [http://www.marchofdimes.com/peristats/]

51. McCann KJ, Twomey JE, Caldwell D, Soave R, Fontaine LA, Lester BM: Services used by perinatal substance-users with child welfare involvement: a descriptive study. Harm Reduct J 2010, 7:19.

52. Burkett G, Gomez-Marin O, Yasin SY, Martinez M: Prenatal care in cocaineexposed pregnancies. Obstet Gynecol 1998, Aug:193-200.

53. Schaper AM, Rooney BL, Kay NR, Silva PD: Use of the Edinburgh Postnatal Depression Scale to identify postpartum depression in a clinical setting J Reprod Med 1994, 39:620-624.

54. Mayberry $L$, Horowitz JA, Declercq E: Depression symptom prevalence and demographic risk factors among U.S. women during the first 2 years postpartum. J Obstet Gynecol Neonatal Nurs 2007, 36:542-549.

55. Selected Chronic and Other Health Conditions By Age and Gender. [http://hawaii.gov/health/statistics/hhs/hhs_08/hhs08t46.pdf].

56. Field T, Diego M, Hernandez-Reif M: Prenatal depression effects on the fetus and newborn: a review. Infant Behav Dev 2006, 29:445-455.

57. Hawaii State Department of Health: Medicaid/QUEST Birth Outcomes Fact Sheet.[http://hawaii.gov/health/family-child-health/mchb/prams-doc/ medicaid].

doi:10.1186/1477-7517-9-5

Cite this article as: Wright et al:: Implementation and evaluation of a harm-reduction model for clinical care of substance using pregnant women. Harm Reduction Journal 2012 9:5.

\section{Submit your next manuscript to BioMed Central and take full advantage of:}

- Convenient online submission

- Thorough peer review

- No space constraints or color figure charges

- Immediate publication on acceptance

- Inclusion in PubMed, CAS, Scopus and Google Scholar

- Research which is freely available for redistribution

Submit your manuscript at www.biomedcentral.com/submit
C) Biomed Central 